\title{
A preliminary study of Aminoglycoside Modifying Enzymes (AMEs) of Multiple Antibiotic Resistance of Methicillin-resistant Staphylococcus aureus (MRSA) isolated from clinical specimens in Al-Diwaniya/Iraq
}

\author{
Firas Srhan Abd Al- Mayahi* \\ Biology Department, College of the Science/ University of Al-Qadisiyah, P.O.Box.1895, Diwaniyah / Iraq
}

Received: June 6, 2020; Revised: Sept 15, 2020; Accepted: Nov 11, 2020

\begin{abstract}
Staphylococcus aureus (SA) plays a significant role in numerous serious life-threatening infections that present a major challenge to public health in controlling it, especially those resistant to methicillin (MR) known as (MRSA). These pathogens have resistance to other classes of antimicrobial agents including aminoglycoside molecules which mostly resist it through three types of medically significant enzymes: APH (3')-III, ANT (4')-I and (6')/APH(2”). In this paper, seventy-two MRAS were isolated from different lesions from Al-Diwaniya teaching hospital, and Maternity and Children teaching hospital, during the period from January to July 2018. Disc diffusion method, minimum inhibitory concentration(MIC), and bactericidal (MBC) were carried out to MRAS strains subjected to phenotype and genotype identification as well as to detect AMEs genes. Susceptibility of 29 drugs of MRAS strains was: $100 \%$ susceptible to vancomycin and chloramphenicol, but $100 \%$ resistant to penicillin, cefoxitin, ceftriaxone, aztreonam, and nitrofurantoin. Thus, a (72.2\%) of MRAS were found to be either MDR or XDR including 20 aminoglycoside resistant (AR) strains. Multiple antibiotic resistance (MAR) index of a total of 20(100\%)AR strains were recorded high values $>0.2$ ranged(0.48-0.83) from the maximum MAR index:1. Moreover, MIC and MBC values of vancomycin, for S. aureus, ranged from $2 \mu \mathrm{g} / \mathrm{mL}$ to $8 \mu \mathrm{g} / \mathrm{mL}$. Phenotype resistance of MRSA strains to aminoglycoside molecules was: kanamycin 20(27.8\%)tobramycin 18(25\%); gentamicin 16(22.2\%); amikacin 14(19.4\%); and netilmicin 8(11.1\%). PCR analysis led to all 100\% MRSA caring for the mecA gene. Frequency of genes encoding aminoglycosides resistance aac(6')/aph (2”);80\%, aph (3')-IIIa;45\%, and ant (4')-Ia; 35\%. The aac(6')/aph (2”) and ant (4')-Ia genes was the only determinant of resistance in 5 and 1 strains respectively. Correlation between MRSA-AR strains and AMEs genes was $90 \%$. In conclusion, MRSA strains harbouring the mecA gene are currently widely distributed in the Al-Diwaniya governorate. Co-production with AMEs may increase the risk of the spreading of multiple drug resistance clinical strains in communities and hospitals.
\end{abstract}

Keywords: MRSA, MDR, XDR, MAR, mecA gene, AME genes.

\section{Introduction}

Opportunistic Staphylococcus aureus (SA) infections are among the significant bacterial infections in the inpatients and outpatients (Goudarzi et al., 2019c; Baines et al., 2019; Xu et al.,2019; Kavusi et al., 2019; Elshabrawy et al., 2020) and the most serious worldwide especially which show resistance to methicillin (MR) drug abbreviated called MRSA (Peacock et al., 2015; Gajdács, 2019; Goudarzi et al.,2019e; Hadyeh et al.,2019 Navidinia et al., 2019). MRSA has been classified within the high resistance priority tiers (WHO, 2017). Gene is responsible for MRSA named mecA(Cikman et al., 2019). This gene is encoded to important protein in the synthesis of MRSA cell wall it is termed an acronym PBP2', while abbreviated SCCmec refers to the chromosomal elements transfer of this protein (Gajdács, 2019). Therefore, MRSA infections cure is considered a major public health concern (Goudarzi et al., 2019d). It causes much mortality of patients because of multiple drug resistance to antimicrobial categories (Watkins et al., 2019). This will reduce therapeutic options for infections caused by MRAS strains (ElFeky et al., 2019). Aminoglycosides are mostly used in the treatment of infection that caused by staphylococcal bacteria when it combination with glycopeptide and $\beta$-lactam drugs (Kavusi et al., 2019), while lincosamide, streptogramin B, and macrolide antibiotics are used as alternatives in treating such infections. (Razeghi et al., 2019). Thus, currently, MRSA strains possess multiple drug resistance (MDR) including the previously mentioned(Khosravi et al., 2017). Development of this resistance is strongly associated with the production of aminoglycoside modifying enzymes (AMEs) which is the majority mechanism to inactivate aminoglycoside molecules(Garneau-Tsodikova and Labby, 2016; SeyediMarghaki et al., 2019). Aph (3')-IIIa, ant (4')-Ia and $\operatorname{aac}\left(6^{\prime}\right) /$ aph (2”) genes are encoded to the most prevalent types of AMEs which are aminoglycoside-3'-Ophosphoryltransferase III, aminoglycoside-4'-O-

\footnotetext{
* Corresponding author e-mail: firas.abd@qu.edu.iq.
} 
nucleotidyltransferase $\quad \mathrm{I}$ and aminoglycoside-6'-Nacetyltransferase/2"-

phosphoryltransferaserespectively(Ramirez and Tolmasky,2010; Namvar et al., 2017). Medically, in staphylococci these enzymes that are known abbreviation [(APH (3')-III, ANT (4')-I and (6')/APH(2”)] are the most frequent AMEs and, which inactivate aminoglycosides of curative importance including respective kanamycin, tobramycin, and gentamicin (Klingenberg et al., 2004; Szymanek-Majchrzak, et al.,2018a).In different parts of the world including the Middle East, there are several neoteric studies expounding the growing prevalence of AMEs in MRSA strains(Goudarzi et al., 2018; SeyediMarghaki et al., 2019; Kavusi et al.,2019; Beigverdi et al.,2019). Nevertheless, in Iraq, the resistance problem of antimicrobial drugs is exacerbated by the overuse and misapply of them. There is no systematic national control of AR, scanty data is available to identify this problem, and there is no database of the genes encoding AMEs among gram-positive bacteria especially MRSA strains. So, the study aimed to assess the occurrence of genes encoding clinically important AMEs such as aph (3')-IIIa, ant (4')-Ia, and aac(6')/aph (2"), and to estimate the relationship between MRSA phenotypes of aminoglycosides resistance and the occurrence of genes responsible for this resistance in patients were attending to Al-Diwaniya hospitals.

\section{Methodology}

\subsection{The population of the study, S. aureus, and MRSA} identification

For the period January to July 2018, 72 MRSA were isolated from different lesions(wound, abases, throat swab, blood, and urine) from randomly the 72 patients(without data related patients) were attending to Al-Diwaniya teaching hospital, and Maternity and Children teaching hospital which is two mains hospitals in Al-Diwaniya province centre of Iraq. Bacterial isolates were identified depending on the traditional morphological(Gram stain/ Himedia, India) and bacteriological tests (Haemolysis on blood agar, mannitol salt medium / Oxoid, UK, and coagulase production) in microbiology laboratory belong to the Faculty of Science- University of Al-Qadisiyah. The media were incubated at $37^{\circ} \mathrm{C}$ for 48 hours according to the method of(Forbes et al., 2007). All S. aureus isolates were tested for detecting phenotypic MRSA depending on the cefoxitin disc-diffusion method (Kirby-Bauer) following (CLSI, 2019)

\subsection{Antibacterial susceptibility testing}

Antibacterial sensitivity patterns of the MRSA strains were performed through Bauer et al. (1966) and CLSI (2019), on Mueller-Hinton medium (Oxoid, UK) plates. Bacterial inoculum was modified according to the 0.5 Table 1:Oligonucleotides sequence of primes used to encoding genes of AMEs and PBP2'.

\begin{tabular}{llllll}
\hline Gene target & $\begin{array}{l}\text { Forward primer } \\
\text { ('5 to 3') }\end{array}$ & $\begin{array}{l}\text { Reverse primer } \\
\text { ('5 to 3') }\end{array}$ & $\begin{array}{l}\text { Amplicon } \\
\text { size (bp) }\end{array}$ & $\begin{array}{l}\text { Annealing } \\
\text { temperature }\end{array}$ & Reference \\
\hline mecA & aaaatcgatggtaaaggttggc & agttctgcagtaccggatttgc & 533 & $55^{\circ} \mathrm{C}$ & Munger and Kelly, (1973) \\
ac(6')/aph (2”) & gaa gta cgc aga aga ga & aca tgg caa gct cta gga & 508 & $54^{\circ} \mathrm{C}$ & Choi et al.(2003) \\
aph (3')-IIIa & ggctaaaatgagaatatcaccgg & ctttaaaaaatcatacagctcgcg & 526 & $55^{\circ} \mathrm{C}$ & Vakulenko et al. (2003) \\
ant (4')-Ia & tggggatgatgttaaggc & gcgtttgacacatccac & 670 & $50^{\circ} \mathrm{C}$ & Riesen and Perreten. (2009). \\
\hline
\end{tabular}

McFarland tube. Antibacterial discs were selected carried out based on the (CLSI, 2019). All isolates tested for sensitivity of 10molecules classes were divided into 29 antibacterial agents, which are : penicillin (PEN, 10units), cefoxitin (FOX, $30 \mu \mathrm{g}$ ), ceftriaxone (CRO, $30 \mu \mathrm{g}$ ), ceftazidime (CAZ, $30 \mu \mathrm{g})$, cefotaxime (CTX,30 $\mu \mathrm{g}$ ), amoxicillin/clavulanic acid (AUG, $30 \mu \mathrm{g}$ ), kanamycin $(\mathrm{K}, 30 \mu \mathrm{g}$ ), netilmicin (NET, $30 \mu \mathrm{g}$ ), amikacin (AK, 30 $\mu \mathrm{g}$ ), gentamicin (GM, $10 \mu \mathrm{g}$ ), tobramycin (TOB,10 $\mu \mathrm{g}$ ), aztreonam (ATM, $30 \mu \mathrm{g}$ ), ciprofloxacin (CIP, $5 \mu \mathrm{g}$ ), moxifloxacin(MFX, 5 $5 \mu \mathrm{g}$ ), ofloxacin (OFX, 5 $\mu \mathrm{g})$,norfloxacin (NOR, $10 \mu \mathrm{g})$, tetracycline (T, 30 $\mu \mathrm{g})$, doxycycline (DXT, $30 \mu \mathrm{g}$ ), trimethoprim (TM, $5 \mu \mathrm{g}$ ), trimethoprim/sulfamethoxazole (SXT, $25 \mu \mathrm{g}$ ), chloramphenicol (C, $30 \mu \mathrm{g})$, nitrofurantoin (NI, $300 \mu \mathrm{g}$ ), vancomycin(VA, 30 $\mu \mathrm{g}$ ), imipenem (IMP, $10 \mu \mathrm{g}$ ), erythromycin $(\mathrm{E}, 15 \mu \mathrm{g})$, rifampin $(\mathrm{RA}, 5 \mu \mathrm{g})$, teicoplanin

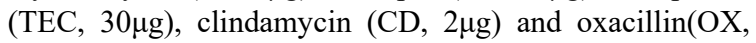
$5 \mu \mathrm{g}$ ) (Bioanalyse, Turkey and Mast Diagnotics, UK). Furthermore, the MRSA strains were stratified to MDR and XDR based on (Magiorakos et al., 2012). A laboratory stock culture of genus S. aureus ATCC 25923 was used as a quality control organism to confirm the accuracy of the antibacterial disks. Strain giving intermediate sensitivity was calculated as resistant. MICs and MBCs values were detected (Andrews, 2001) and calculation of the multiple antibiotic resistance (MAR) index of 20 MRSA-AR was conducted based on (Krumpernam, 1983; Riaz et al., 2011).

\subsection{Isolation of deoxyribonucleic acid}

DNA isolation was perfect using a specific procedure of (+)ve bacteria (proteinase $\mathrm{K}$ ) and according to the manufacturer's instructions of Kit (Geneaid, USA).

\subsection{PCR analysis}

PCR assay was done by components that were accumulated in a PCR tube and mixed under sterile conditions on an ice bag. The reaction was performed using a $25 \mu \mathrm{l}$ mixture including $12.5 \mu \mathrm{l}$ Go Tag Green Master mix(Promega, USA), $2.5 \mu \mathrm{l}$ of $10 \mu \mathrm{M}$ each primer (Macrogen, Korea), $5 \mu \mathrm{l}$ of genomic DNA, and $2.5 \mu \mathrm{l}$ nuclease-free water. The PCR program was done with a (Biometra, Germany). Universal specific primer sequence listed in table 1 , the amplification conditions of each primer of ant (4')-Ia, mecA, aph (3')-IIIa, aac(6')/aph (2') genes describe in the same references in table 1 . The amplifications were electrophoresed (Biometra, Germany)through $1.5 \%$ agarose gel pretreated with ethidium bromide, utilizing a UV imager(Biometra, Germany). The results were documented. Times of electrophoresis were at 75 volts for 90 minutes. Molecular weight DNA markers were used (Ladder 100 bp Promega, USA). 


\subsection{Analysis}

$\chi 2$ test was used to determine the significant frequencies of resistance results. P-value $<0.01$, Prism 5 (Graphpad Software Inc., San Diego, CA, USA).

\section{Results}

72 MRSA strains were obtained from patients who were suffering from various infections. The main different lesions of this causative agent were: urine 32 (44.5\%), wounds 18(25), abases $13(18.0 \%)$, blood cultures 5 (6.9\%), and throat swabs 4 (5.6\%). Of these $72.2 \%$ were found to be either MDR or XDR, thus a (44/72; 61.1\%) of MRSA were found to be MDR while the remaining $(8 / 72 ; 11.1 \%)$ were XDR. Whole, $100 \%$ strains were sensitive to vancomycin(MICs and MBCs values ranged 2 $\mu \mathrm{g} / \mathrm{mL}$ to $8 \mu \mathrm{g} / \mathrm{mL}$.) and chloramphenicol. Strains exhibited significant frequencies of antibacterial agents resistance $(\mathrm{P}<0.01)$ (Figure 1$)$. The highlight indicates cases considered to be resistant to the respective drugs. Penicillin, cefoxitin, ceftriaxone, aztreonam, and nitrofurantoin showed a resistance of $100 \%$ from all the isolates. A high rate of resistance (94.5, 88.9, 83.3, 79.2, 77.8, 73.6, and 61.2)\% showed that $S$. aureus to ceftazidime, cefotaxime, trimethoprim, erythromycin, oxacillin, tetracycline, and teicoplanin respectively. The resistance of clindamycin and Amoxicillin/clavulanic acid were $37.5 \%$ and $30.6 \%$. Also, the most effective of antibacterial agents were imipenem, rifampin, ofloxacin, doxycycline, moxifloxacin, ciprofloxacin, norfloxacin and trimethoprim/sulfamethoxazole with resistance rates $11.1 \%, 11.1 \%, 22.2 \%, 22.2 \%, 26.4 \%, 27.8 \%, 27.8 \%$ and $33.3 \%$ (Figure 1).

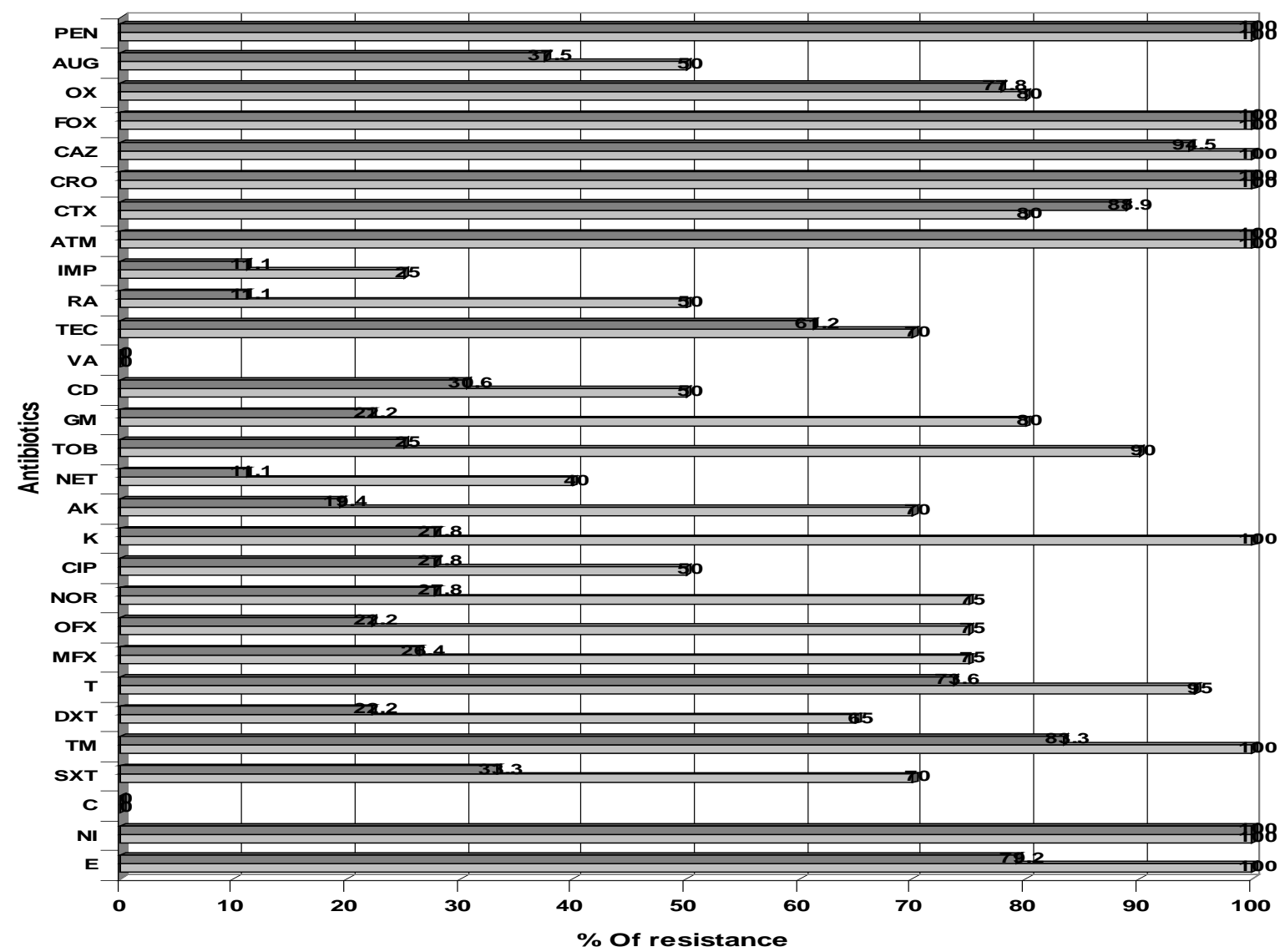

Figure 1. Comparison between the rates of resistance for 72 strains of MRSA(A) and 20 strains of MRSA which show resistance to aminoglycosides(B).

PEN, penicillin; AUG, amoxicillin-clavulanic acid; OX, oxacillin;FOX, cefoxitin;CAZ, ceftazidime; CRO, ceftriaxone; CTX, cefotaxime;ATM, aztreonam;IMP, imipenem;RA, rifampin; TEC teicoplanin; VA, vancomycin; CD, clindamycin; GM,gentamicin; TOB, tobramycin;NET, netilmicin; AK, amikacin; K, kanamycin; CIP, ciprofloxacin;NOR, norfloxacin; OFX, ofloxacin;MFX,moxifloxacin;

$\mathrm{T}$, tetracycline;DXT,doxycycline;TM,trimethoprim;SXT,trim
ethoprim/sulfamethoxazole;C,chloramphenicol;NI,nitrofur antoin; E, erythromycin.

The aminoglycosides resistance rate among the tested S. aureus strains ranged from $27.8 \%-11.1 \%$. The present study showed that netilmicin was the most potent aminoglycoside; its overall potency over the isolated $S$. aureus was $11.1 \%$, while amikacin, gentamicin, tobramycin, and kanamycin were $19.4 \%, 22.2 \%, 25 \%$, and $27.8 \%$ respectively. The full $(100 \%)$ dissemination of the mecA gene in MRSA strains is shown in (Figure2). 


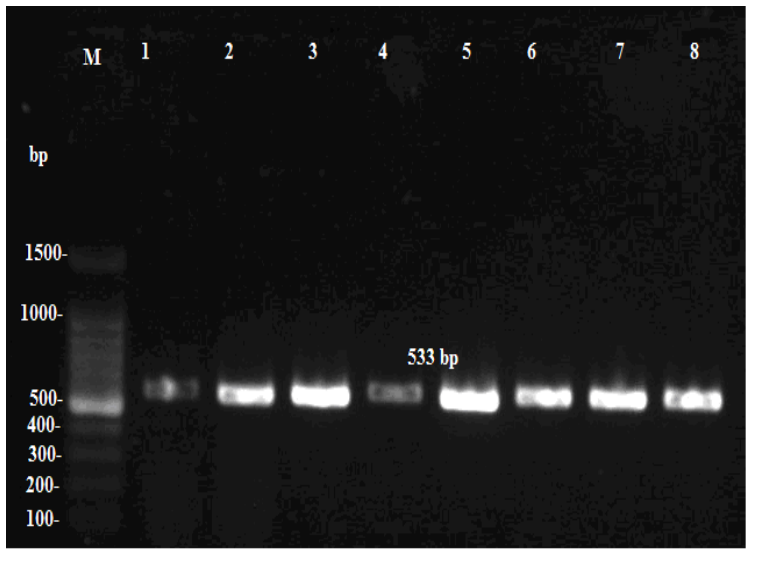

Figure 2.Image of electrophoresis gel of $S$. aureus. Lane M, PCR ladder (100-1500 bp), amplified products of the mecA gene (533 bp).Lanes (1-8) positive results.

Out of 20, MRSA was AR eighteen (90\%) carrying at minimum 1 of genes encoded AR. The most common of genes encoded AMEs were aac(6')/aph (2");80\%, aph (3')-IIIa;45\%, and ant (4')-Ia; 35\% (Figure 3,4 and 5 respectively).

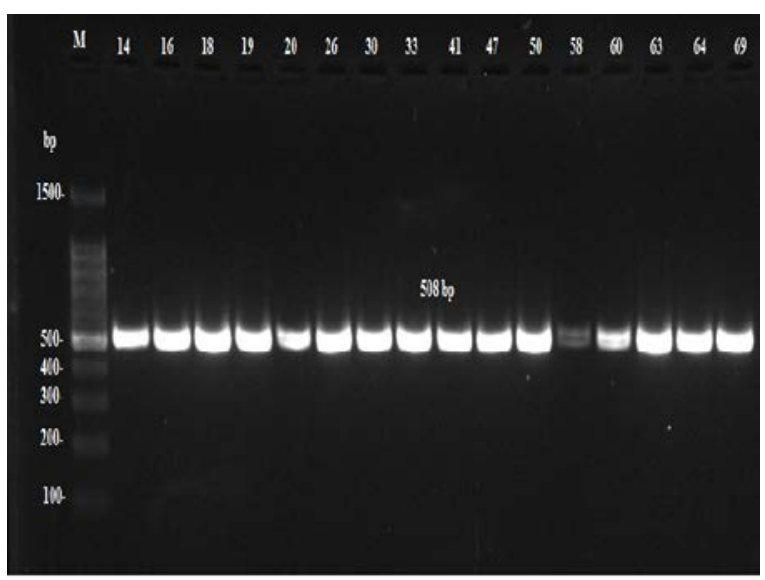

Figure 3. Image of electrophoresis gel of $S$. aureus. Lane M, PCR ladder (100-1500 bp), amplified products of the ac(6')/aph (2”)gene (508 bp).Lanes (14,16,18,19,20,26,30,33,41,47,50,58, $60,63,64,69)$

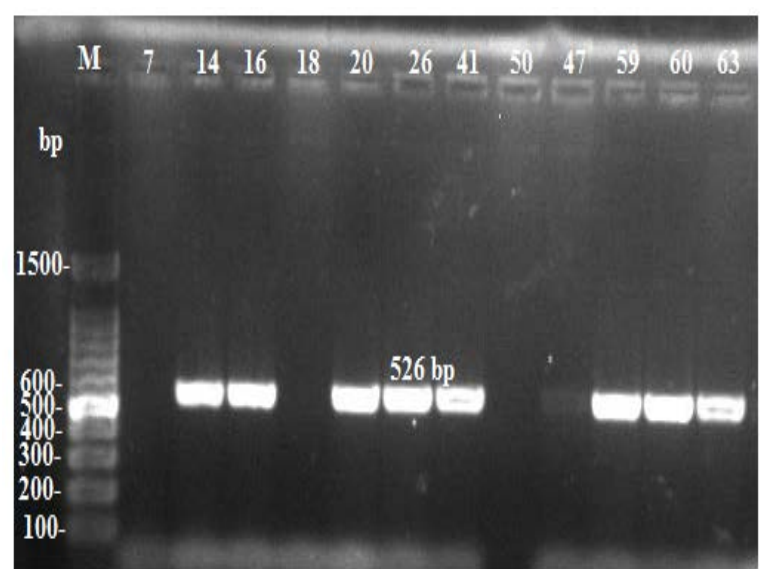

Figure 4.Image of electrophoresis gel of $S$. aureus. Lane M, PCR ladder (100-1500 bp), amplified products of the aph (3')-IIIagene (526bp).Lanes (14,16, 20,26,41,47,59, 60,63) positive results, lanes $(7,18,50)$ negative results.

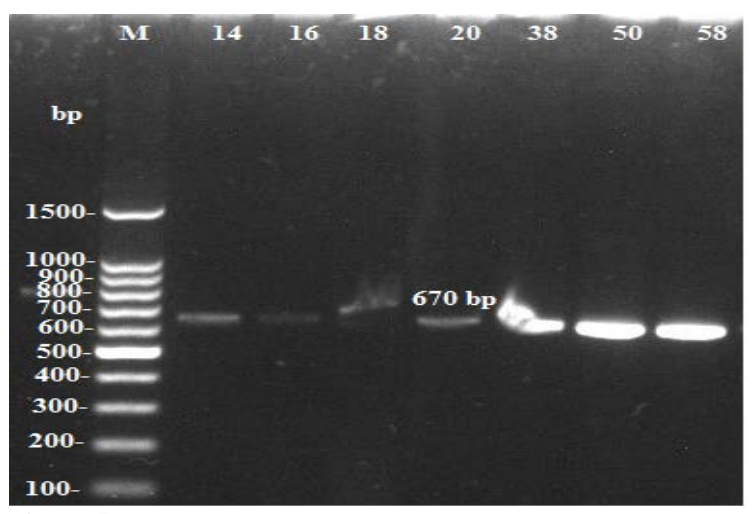

Figure 5. Image of electrophoresis gel of S. aureus. Lane M, PCR ladder (100-1500 bp), amplified products of the ant (4')-Ia gene (670 bp).Lanes (14, 16,18, 20,26,38,50,58) positive results.

Interestingly, it is observed that all(100\%) strains in which positive results of AR genes were resistant to at least three aminoglycoside molecules. The highest resistance of 20 AR isolates compares with 72 MRSA isolates against all drugs, especially aminoglycoside as mentioned in figure $1.100 \%$ of MRSA-AR were either $\operatorname{MDR}(12 / 20 ; 60 \%) \quad$ or $\operatorname{XDR}(8 / 20 ; 40 \%)$. The dissemination, frequency of co-occurrence genes encoding AMEs, and relationship within phenotypic AR among MRSA harboring mecA gene are listed in Table (2).

Table 2: Phenotypic and molecular analysis of aminoglycosides resistance patterns possessed 20 MRSA strains harboring the mecA gene.

\begin{tabular}{|c|c|c|c|c|c|}
\hline No. & Phenotypic & No. (\%) & Genotypic & No. (\%) & Profile type \\
\hline G1 & NET, AK, GM, TOB, K & $6(30)$ & aac(6')/aph (2") & $6(33.3)$ & 3G2,2G3,1G4 \\
\hline G2 & AK, GM, TOB, K & $6(30)$ & aph (3')-IIIa & 0 & - \\
\hline G3 & NET, GM, TOB, K & $2(10)$ & ant (4')-Ia & $1(5.6)$ & G6 \\
\hline G4 & GM, TOB, K & $2(10)$ & $\operatorname{aac}\left(6^{\prime}\right) / \operatorname{aph}\left(2^{\prime}\right)+\operatorname{aph}\left(3^{\prime}\right)-I I I a$ & $5(27.8)$ & $3 \mathrm{G} 1,2 \mathrm{G} 2$ \\
\hline G5 & AK TOB, K, & $1(5)$ & $\operatorname{aac}\left(6^{\prime}\right) / a p h\left(2^{\prime \prime}\right)+\operatorname{ant}\left(4^{\prime}\right)-I a$ & $2(11.1)$ & $1 \mathrm{G} 2,1 \mathrm{G} 4$ \\
\hline G6 & TOB, K & $1(5)$ & aph (3’)-IIIa + ant (4')-Ia & $1(5.6)$ & G5 \\
\hline \multirow[t]{2}{*}{ G7 } & K & $2(10)$ & $\operatorname{aac}\left(6^{\prime}\right) / \operatorname{aph}\left(2^{\prime \prime}\right)+\operatorname{aph}\left(3^{\prime}\right)-I I I a+\operatorname{ant}\left(4^{\prime}\right)-I a$ & $3(16.7)$ & $3 G 1$ \\
\hline & Total & $20(100)$ & & $18(100)$ & \\
\hline
\end{tabular}

The most frequent $11 / 18(61.1 \%)$ of MRSA strains which comprise AMEs genes were as combinations or simultaneously. Correlation between the AR patterns and their presence of plasmid-mediated AR genes among MRSA isolates tested are shown in (Table 2 and 3). The results showed that there is $100 \%$ compatibility between the presence of aac(6')/aph (2") and resistance to gentamicin. It was discovered in all strains resistant to gentamicin (Table 3). Lastly, only 2 strains of MRSA were resistant to kanamycin did not give any result with AMEs genes. 
High values $>0.2$ ranged(0.48-0.83) from the maximum MAR index(1) were documented in all 20(100\%)MRSAAR strains which summarize in figure 6 .

Moreover, the relationship between phenotypic resistance indicators and AR genes among MRSA strains was mentioned in Table(4)
Table 3: Relatedness between phenotypic and the main molecular description of aminoglycosides resistance patterns in a total of 18 MRSA strains harboring AMEs genes.

\begin{tabular}{lllllll}
\hline $\begin{array}{l}\text { Genotypic } \\
\text { description of AMEs }\end{array}$ & No. (\%) & \multicolumn{3}{l}{ (\%) Of phenotypic expression } \\
& & AMEs \\
& NET & AK & GM & TOB & K \\
\hline aac(6')/aph (2”) & $16(80)$ & 50 & 75 & 100 & 100 & 100 \\
aph (3')-IIIa & $9(45)$ & 66.7 & 100 & 88.9 & 100 & 100 \\
ant (4')-Ia & $7(35)$ & 42.8 & 71.4 & 71.4 & 100 & 100 \\
\hline
\end{tabular}

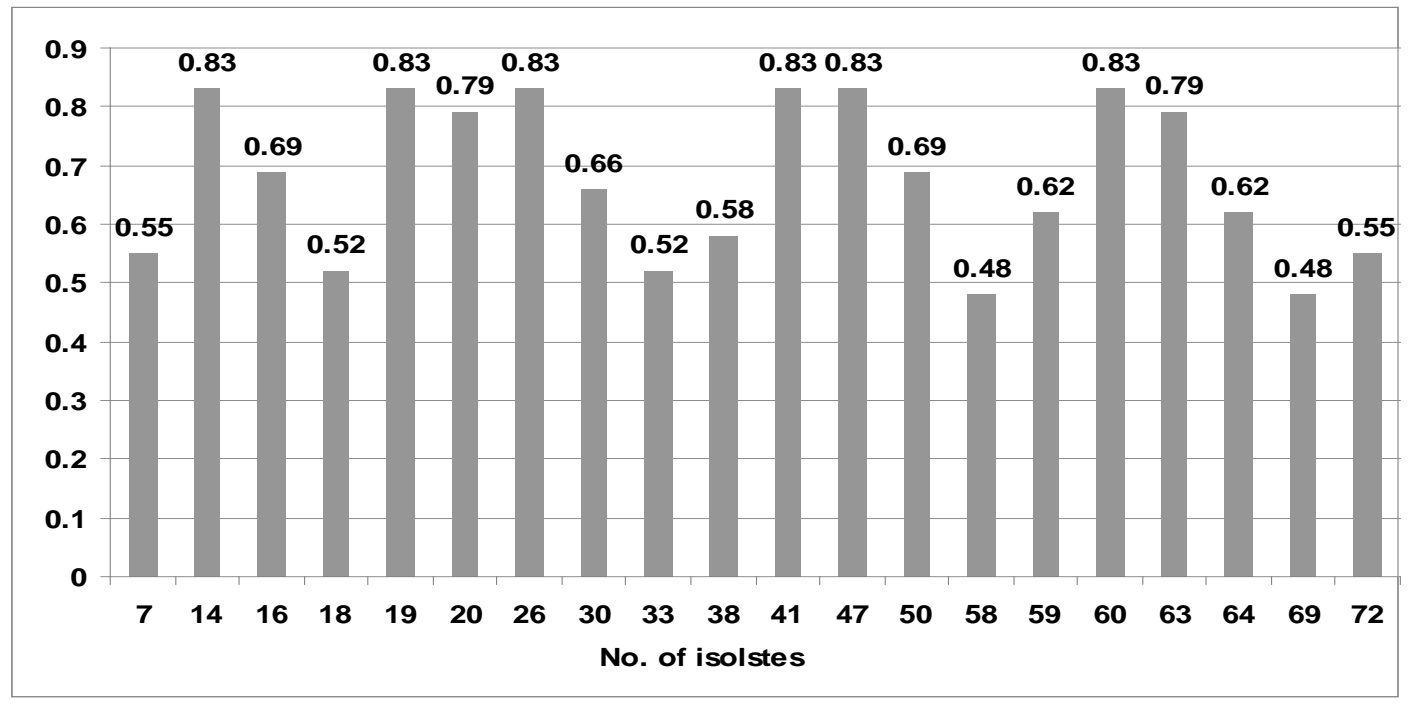

Figure 6. MAR indexes of 20 aminoglycosides resistance MRSA isolates.

Table 4:Dissemination of multiple resistance of drug patterns among MRSA-AR genes.

\begin{tabular}{|c|c|c|c|c|c|c|}
\hline \multirow[t]{2}{*}{ No. of strain } & \multirow[t]{2}{*}{ mecA gene } & \multicolumn{2}{|c|}{ Phenotypic profile } & \multicolumn{3}{|c|}{ AMEs genes profile } \\
\hline & & MDR / XDR & MAR index & $\operatorname{aac}\left(6^{\prime}\right) / a p h\left(2^{\prime \prime}\right)$ & aph (3’)-IIIa & ant (4')-Ia \\
\hline S7 & + & MDR & 0.55 & - & - & - \\
\hline S14 & + & $\mathrm{XDR}$ & 0.83 & + & + & + \\
\hline S16 & + & MDR & 0.69 & + & + & + \\
\hline S18 & + & MDR & 0.52 & + & - & + \\
\hline S19 & + & XDR & 0.83 & + & - & - \\
\hline S20 & + & XDR & 0.79 & + & + & + \\
\hline S26 & + & $\mathrm{XDR}$ & 0.83 & + & + & - \\
\hline S30 & + & MDR & 0.66 & + & - & - \\
\hline S33 & + & MDR & 0.52 & + & - & - \\
\hline S38 & + & MDR & 0.58 & - & - & + \\
\hline S41 & + & XDR & 0.83 & + & + & - \\
\hline S47 & + & XDR & 0.83 & + & + & - \\
\hline S50 & + & MDR & 0.69 & + & - & + \\
\hline S58 & + & MDR & 0.48 & + & - & - \\
\hline S59 & + & MDR & 0.62 & - & + & + \\
\hline S60 & + & XDR & 0.83 & + & + & \\
\hline S63 & + & XDR & 0.79 & + & + & \\
\hline S64 & + & MDR & 0.62 & + & - & \\
\hline S69 & + & MDR & 0.48 & + & - & \\
\hline S72 & + & MDR & 0.55 & - & - & - \\
\hline Total & 20 & & & 16 & 9 & 7 \\
\hline
\end{tabular}




\section{Discussion}

Antimicrobial stewardship is important to prevent the spread and expansion of MDR strains and to overcome the development of increased resistance to antibiotics in general and aminoglycoside in particular, and continued national surveillance programs are crucial. Aminoglycosides are broad-spectrum bactericidal antibiotics of high potency that have been traditionally used for the treatment of serious and of life-threatening Gram-negative and some Gram-positive infections (Zacharczuk et al., 2011; Becker and Cooper, 2013; Garneau-Tsodikova and Labby, 2016). In different parts of the world including in Iraq, aminoglycosides are used for treating severe infections caused by Gram-Positive bacteria. As a result, multiple resistance determinants to these antimicrobial agents have emerged in various pathogenic microbes including MRSA. This organism is a major public health concern representing about $60 \%$ of $S$. aureus isolated from hospitalized patients in countries such as the USA and Brazil in the last years(Dos Reis et al., 2020).

72 MRSA strains were obtained from patients who were suffering from various infections. The main different lesions of this causative agent were: urine 32 (44.5\%), wounds 18(25), abases $13(18.0 \%)$, blood cultures 5 (6.9\%), and throat swabs 4 (5.6\%). Of these $72.2 \%$ found to be either MDR or XDR, thus a $(44 / 72 ; 61.1 \%)$ of MRSA were found to be MDR while the remaining $(8 / 72 ; 11.1 \%)$ were XDR. The full (100\%) dissemination of the mecA gene in MRSA strains are in (Figure2 and Table 4).This finding matches with other reports in West BankPalestine and Sri Lanka that found all 112 and 94 S. aureus (100\%) isolated from different lesions as MRSA strains were caring mecAgene (Hadyeh et al., 2019; McTavish et al., 2019) respectively. This agrees with Goudarzi et al. (2019b) in Iran as 78.6\% (66/84) of MRSA strains were found to be MDR. The vast majority our results were matched with another report of MRSA strains isolated from the holy shrine in Najaf, Iraq which found that most strains(100\%) were resistant to penicillin, ceftriaxone, ceftazidime, $(72.7 \%)$ to erythromycin, and the most susceptible(100\%) to vancomycin, chloramphenicol,(72.3\%) to gentamicin and 8/11(72.7\%) of MRSA strains were found to be MDR(Al-Mohana et al., 2012). Based on the above results, it can be said that vancomycin is considered the best choice of treatment MRSA infections in various parts the world (SzymanekMajchrzak et al., 2018b) including Iraq, despite some resistance cases that have been observed in this area (AlJumaily et al., 2012; ElFeky et al.,2019) and the world (Szymanek-Majchrzak et al., 2018b). Also, these results were close to other results of a study documented in Sulaimani city, Iraq concerning the resistance MRSA of a $\beta$-lactams drug (Al-Jumaily et al., 2012). Moreover, resistance of $\beta$-lactam, vancomycin, and gentamicin was documented in MRSA strains which were isolated from West Bank-Palestine (Hadyeh et al., 2019). Due to the widespread and indiscriminate use of antibiotics in treatment, a major problem has emerged as the multiple resistance of these drugs from different bacterial species, especially $S$. aureus. This maybe via the biofilms formation which increases from the pathological ability(Gomes et al., 2019).Interestingly, in this investigation there was a low level of AR among MRSA strains compared with other studies in Iraq and other parts of the world, which may be explained by a decrease in the number of MRSA strains from the various regions of central Iraq or by low- level description of this drug in the treatment infections of this pathogen. For more than half a century, aminoglycoside has been mainly used against gram-negative and some gram-positive bacterial infections (Garneau-Tsodikova and Labby, 2016), and this reinforces the second reason. The first cause may be close to reality and corresponds to an antibiotic sensitivity analysis performed in the Al-Diwaniya governorate (unpublished) which documented that approximately $30.5 \%(7 / 23)$ of MRSA strains were gentamicin resistant (Al-Mayahi, 2018). Thus, ElFeky et al. (2019)who found that 63\%(63/100)of MRSA strains were resistant to gentamicin. The resistance pattern in the Al-Diwaniya governorate is somewhat harmonious with other investigations in the Najaf governorate centre Iraq, which showed that MRSA strains were $27.7 \%$ (15/54) resistant to gentamicin(Al-Mohana et al., 2012). Aminoglycoside molecules still have significant effects alone or in combination with other molecules in treating infections causing staphylococci, despite the emergence of resistance to them in different parts of the world (Kavusi et al., 2019). In a previous study, Goudarzi et al. (2019e) found that MRSA strains and AMEs production have been developed rapid resistance to a wide range of drugs including tetracyclines, and this agreed with our study at a rate of resistance (73.6\%). High values $>0.2$ ranged(0.480.83 ) from the maximum MAR index Baines et al. (2018) were documented in all 20(100\%)MRSA-AR strains. A MAR index resistance to $>0.20$ antibiotics indicates that bacteria originate from an environment where antibiotics are freely available, leading to a high potential for misuse and a 'high-risk' source of contamination (Krumpernam, 1983; Riaz et al., 2011). There is scanty information regarding the level of antibiotics resistant to MRSA strains associated with multiple infections in Iraq, thus possibly posing a public health challenge for physicians. Consequently, this study determined the MAR index of these isolates. However, the elevation of MAR index values was observed in our investigation (Figure 5and Table 4). All MRSA-AG strains had MAR index of $>0.20$, confirming that there was widespread use of antibiotics and high selective pressure in the Al-Diwaniya population. The MAR indices obtained in the present study is a probable signal that a very major ratio of the MRSA strains was displayed to numerous antimicrobial drugs. The high MAR identified in the present research warns us that any use of antibiotics in treatment should be preceded by an accurate diagnosis of the causative agents, followed by an antimicrobial sensitivity test. Such a thing will not only contribute to the effective use of these drugs but also will control the prevalence of resistant isolates of antibiotics in Iraqi hospitals and communities.

Out of 20, MRSA was AR eighteen (90\%)carrying at minimum 1 of genes encoded AR. The most genes encoded AMEs common were namely aac(6')/aph (2”);80\%, aph (3')-IIIa;45\%, and ant (4')-Ia; 35\% (Tables 2 and 4). Many reports from Iran have reported that the aac(6')/aph (2") gene was the most frequent AMEs gene followed by aph (3')-IIIa gene and ant (4')-Ia gene in MRSA isolates(Fatholahzadeh et al., 2009; Emaneini et 
al., 2013; Mohammadi et al., 2014; Khosravi et al., 2017; Khoramrooz et al., 2017; Seyedi-Marghaki et al.,2019; Goudarzi et al.,2019d), from Turkey(Ardic et al., 2006), from Australia (Baines et al.,2019), from India(Perumal et al., 2016) and Europe(Vanhoof et al., 1994). However, the prevalence of MRSA strains containing aac(6')/aph (2”) gene in Al-Diwaniya (80\%), is similar with Goudarzi et al. (2019a), Szymanek-Majchrzak, et al. (2018a), Baines et al. (2019), Kavusi et al. (2019), Mohammadi et al. (2014) and Mahdiyoun et al. (2016)in Iran(80\%), Europe(80.5\%), Australian clade (79.7\%), Iran(78.3\%), (77.8\%) and (77\%) respectively, and is less compared to similar studies in Iran (97.22\%)(Khoramrooz et al., 2017) and Asian-Australian clade $(93.2 \%)$ (Baines et al.,2019). The results showed there is $100 \%$ compatibility between the presence of aac(6')/aph (2") and resistance to gentamicin (Table 3). It was discovered in all strains resistant to gentamicin. This concordance matches with previous researches(Choi et al., 2003; Yadegar et al., 2009). The present investigation shows that aph (3 ') - IIIa gene was the second dominant gene (45\%), and was in agreement with the reports from, Australia(45.0\%)(Baines et al.,2019), Europe (44\%) (Młynarczyk et al., 2010), Iran(46.3\%) (Goudarzi et al.,2019e) and(46.7\%)(Goudarzi et al.,2019c), while Seyedi-Marghaki et al. (2019) and Khoramrooz et al. (2017) in Iranian work documented rate of this gene in (19\% and $61.1 \%)$ of MRSA strains. Dissemination of ant(4')-I was detected as 35\% (7/20) (Tables 2 and 4). This was similar with other reports from Australia 34.1\% (Baines et al.,2019), Iran 38.6\%(Goudarzi et al.,2018), and less than the ratio mentioned in a big Japanese report (84.5\%) (Ida et al., 2001) and Europe (55.3\%)(SzymanekMajchrzak, et al.,2018b). The presence of the aac(6')/aph (2"),aph (3')-IIIa and ant (4')-Ia genes was sufficient to express the resistance phenotype(100\%) to $\mathrm{GM} / \mathrm{TOB} / \mathrm{K}$, $\mathrm{AK} / \mathrm{TOB} / \mathrm{K}$ and $\mathrm{TOB} / \mathrm{K}$ respectively (Table 3). AAC(6')/APH(2") enzyme grant resistance to aminoglycosides molecules including GM/TOB/K, APH (3')-IIIa grant resistance AK/TOB/K, and ANT (4')-Ia enzyme grant resistance to $\mathrm{TOB} / \mathrm{K}$ (Vakulenko and Mobashery, 2003). The relatedness between phenotypic and genotypic AR with MRSA were $27.8 \%$ and $25 \%$. This relationship was reported in other studies such as (Yadegar et al., 2009; Mohammadi et al., 2014; Khosravi et al., 2017), where the last study recorded a high correlation (72.7\%).

\section{Conclusion}

In conclusion, this is the first paper that provided baseline prevalence data on the presence of AMEs genes in MRSA strains containing the mecA gene in AlDiwaniya governorate in the centre of Iraq which reached alarming tiers; thus, Aminoglycosides should be used carefully by physicians. The execution of a local and global monitoring system to observe antibiotic resistance, particular aminoglycosides, and growing consciousness of AMEs genes among physicians are necessary for guiding empirical therapy-specific measures against a specific pathogen

\section{Acknowledgement}

Thank you for the microbiology laboratory staff at the Al-Diwaniya province hospitals for help with collection specimens, and also thank you for the microbiology laboratory in the Department of Biology in the College and University of the researcher for help in providing a place for research.

\section{Funding}

None.

\section{Conflict of interest}

None.

\section{Authors' contribution sections}

Not applicable.

\section{References}

Al-Jumaily EF, Mohamed DA and Khanaka HH. 2012. Molecular epidemiology and Antibiotic susceptibility patterns of c1inical strains of methicillin resistant Staphylococcus aureus (MRSA) in Sulaimani city-Iraq. Glo Adv Res J Microbiol,1(6): 81- 89.

Al-Mayahi MHM .2018. Bacteriological and molecular study of Staphylococcus aureus bacteria isolated from women breast abscess in Al Qadisiyah governorate.MSc dissertation, The AlQadisiya University, Diwaniya, Iraq.

Al-Mohana AM, Al-Charrakh AH, Nasir FH and Al-Kudhairy MK.2012. Community-acquired methicillin-resistant Staphylococcus aureus carrying mecA and Panton-Valentine leukocidin (PVL) genes isolated from the holy shrine in Najaf, Iraq. J Bacteriol Res, 4(2):15-23.

Andrews JM.2001. Determination of minimum inhibitory concentration. J Antimicrob Chemother, 48(S1):5-16.

Ardic N, Sareyyupoglu B, Ozyurt M, Haznedaroglu T and Ilga U. 2006. Investigation of aminoglycoside modifying enzyme genes in methicillin-resistant staphylococci. Microbiol Res, 161(1):4954.

Baines SL, Jensen SO, Firth N, da Silva AG, Seemann T, Carter GP, Williamson DA, Howden BP and Stinear TP.2019. Remodeling of pSK1 family plasmids and enhanced chlorhexidine tolerance in a dominant hospital lineage of methicillin-resistant Staphylococcus aureus. Antimicrob Agents Chemother, 63(5): e02356-18.

Bauer AW, Kirby WMM, Sherris JC and Turck M. 1966. Antibiotic susceptibility testing by a standardized single disc method. Am J Clin Pathol, 45:493-496.

Becker B and Cooper MA.2013. Aminoglycoside antibiotics in the $21^{\text {st }}$ century. ACS Chem Biol, 8:105-115.

Beigverdi R, Sattari-Maraji A, Jabalameli F and Emaneini M.2019. Prevalence of Genes Encoding AminoglycosideModifying Enzymes in Clinical Isolates of Gram-Positive Cocci in Iran: A Systematic Review and Meta-analysis. Microb Drug Resist, 26(2): 126-135.

Choi SM, Kim S-H, Kim H-J, Lee D-G, Choi J-H, Yoo J-H, Kang J-H, Shin W-S and Kang M-W.2003. Multiplex PCR for the detection of genes encoding aminoglycoside modifying enzymes and methicillin resistance among Staphylococcus species. $J$ of Korean Med Sci, 18(5):631-636. 
Cikman A, Aydin M, Gulhan B, Karakecili F, Kurtoglu MG, Yuksekkaya S, Parlak M, Gultepe BS, Cicek AC, Bilman FB, Ciftci IH, Kara M, Atmaca S and Ozekinci T. 2019. Absence of the mecC gene in methicillin-resistant Staphylococcus aureus isolated from various clinical samples: The first multicenteredstudy in Turkey. J Infect Public Health 12: 528-533.

Clinical and Laboratory Standards Institute.2010. Performance standards for antimicrobial susceptibility testing; twentieth ed. Informational supplement approved standard M07-A8. Wayne, PA, USA.

Clinical and Laboratory Standards Institute .2019. Performance standards for antimicrobial susceptibility testing; twentieth nine ed. Informational Supplement. Approved standard M100. Wayne, PA, USA.

Dos Reis SV, de Couto NMG, Brust FR, Trentin DS, da Silva JKR, Arruda MSP, Gnoatto SCB and Macedo AJ.2020. Remarkable capacity of brosimine b to disrupt methicillinresistant Staphylococcus aureus (MRSA) preformed biofilms. Microb Pathog, 140: 103967.

ElFeky DS, Awad AR, Elshobaky MA and Elawady BA. 2019. Effect of Ceftaroline, Vancomycin, Gentamicin, Macrolides, and Ciprofloxacin against Methicillin-Resistant Staphylococcus aureus Isolates: An In Vitro Study. Surg Infect, 21(2):150-157

Elshabrawy MA, Abouelhag HA, Khairy EA, Marie HSh. and Hakim AS.2020. Molecular divergence of Staphylococcus aureus isolated from Dogs and Cats. Jordan J Biol Sci, 13(2):139-144.

Emaneini M, Bigverdi R, Kalantar D, Soroush S, Jabalameli F, Khoshgnab BN, Asadollahi P and Taherikalani M.2013. Distribution of genes encoding tetracycline resistance and aminoglycoside modifying enzymes in Staphylococcus aureus strains isolated from a burn center. Ann Burns Fire Disasters, 26(2): 76-80.

Fatholahzadeh B, Emaneini M, Feizabadi MM, Sedaghat H, Aligholi M, Taherikalani M and Jabalameli F.2009. Characterisation of genes encoding aminoglycoside-modifying enzymes among meticillin-resistant Staphylococcus aureus isolated from two hospitals in Tehran, Iran. Int $J$ Antimicrob Agents, 33(3):264-265.

Forbes BA, Sahm DF and Weissfeld AS.2007. Bailey and Scott's Diagnostic Microbiology, twelfth ed.Mosby Inc, Maryland Heights, Mo, USA.

Gajdács M.2019. The continuing threat of methicillin-resistant Staphylococcus aureus. Antibiotics.8(2):52.

Garneau-Tsodikova S and Labby KJ.2016. Mechanisms of resistance to aminoglycoside antibiotics: overview and perspectives. Med Chem Comm ,7:11-27.

Gomes F, Martins N, Ferreira ICFR and Henriques M. 2019. Antibiofilm activity of hydromethanolic plant extracts againstStaphylococcus aureus isolates from bovine mastitis. Heliyon, 5: e01728

Goudarzi M, Navidinia M, Beiranvand E and Goudarzi H .2018. Phenotypic and molecular characterization of methicillin-resistant Staphylococcus aureus clones carrying the Panton-Valentine leukocidin genes disseminating in Iranian hospitals. Microb Drug Resist, 24(10):1543-1551.

Goudarzi M, Eslami G, Rezaee R, Heidary M, Khoshnood S, and Nia RS .2019a. Clonal dissemination of Staphylococcus aureus isolates causing nosocomial infections, Tehran, Iran. Iran J Basic Med Sci, 22(3), 238-245.

Goudarzi M, Fazeli M, Eslami G, Pouriran R, Hajikhani B, and Dadashi M .2019b. Genetic Diversity Analysis of Methicillinresistant Staphylococcus aureus Strains Isolated from Intensive Care Unit in Iran. Oman Med J, 34(2), 118-125.
Goudarzi M, Kobayashi N, Hashemi A, Fazeli M and Navidinia M.2019c. Genetic Variability of Methicillin Resistant Staphylococcus Aureus Strains Isolated from Burns Patients. Osong Public Health Res Perspect, 10(3):170-176.

Goudarzi M, Mohammadi A, Goudarzi H, Fazeli M and Sabzehali F.2019d. Genetic Variability and Integron Occurrence in Methicillin Resistant Staphylococcus aureus Strains Recovered from Patients with Urinary Tract Infection. Arch Pediatr Infect Dis, e86189:1-9.

Goudarzi M, Razeghi M, Dadashi M, Miri M, Hashemi A, Amirpour A, Nasiri MJ and Fazeli M .2019e. Distribution of SCCmec types, tetracycline and aminoglycoside resistance genes in hospital-associated methicillin-resistant Staphylococcus aureus strains. Gene Reports, 16:100454.

Hadyeh E, Azmi K, Seir RA, Abdellatief I and Abdeen Z.2019. Molecular Characterization of Methicillin Resistant Staphylococcus aureus in West Bank-Palestine. Front Public Health, 7:(130): 1-9.

Ida T, Okamoto R, Shimauchi C, Okubo T, Kuga A and Inoue M .2001. Identification of aminoglycoside-modifying enzymes by susceptibility testing: epidemiology of methicillin-resistant Staphylococcus aureus in Japan. J Clin Microbiol, 39(9): 31153121.

Kavusi M, Nematimansour F and Mahdiyoun M.2019. The prevalence of antibiotic resistance in methicillin-resistant Staphylococcus aureus and the determination of aminoglycoside resistance gene aac $\left(6^{\prime}\right)-\mathrm{Ie} / \mathrm{aph}\left(2^{\prime \prime}\right)$ isolated from hospitalized patients in Imam Hossein, Loghman Hakim, and Pars hospitals in Tehran using polymerase chain reaction. SJIMU, 27(1):85-94.

Khoramrooz SS, Dolatabad SA, Dolatabad FM, Marashifard M, Mirzaii M, Dabiri H, Haddadi A, Rabani SM, Shirazi HRG and Darban-Sarokhali D.2017. Detection of tetracycline resistance genes, aminoglycoside modifying enzymes, and coagulase gene typing of clinical isolates of Staphylococcus aureus in the Southwest of Iran. Iran J Basic Med Sci, 20(8):912-919.

Khosravi AD, Jenabi A and Montazeri EA .2017. Distribution of genes encoding resistance to aminoglycoside modifying enzymes in methicillin-resistant Staphylococcus aureus (MRSA) strains. Kaohsiung J Med Sci, 33(12): 587-593.

Klingenberg C, Sundsfjord A, Rønnestad A, Mikalsen J, Gaustad $\mathrm{P}$ and Flægstad T. 2004. Phenotypic and genotypic aminoglycoside resistance in blood culture isolates of coagulasenegative staphylococci from a single neonatal intensive care unit, 1989-2000. J Antimicrob Chemother, 54:889e96.

Krumpernam PH .1983. Multiple antibiotic resistance indexing Escherichia coli to identify risk sources of fecal contamination of foods. Appl Environ Microbiol, 46 : 165-170.

Magiorakos AP, Srinivasan A, Carey RB, Carmeli Y, Falagas ME, Giske CG, Harbarth S, Hindler JF, Kahlmeter G, OlssonLiljequist B, Paterson DL, Rice LB, Stelling J, Struelens MJ, Vatopoulos A, Weber JT and Monnet DL.2012. Multidrugresistant, extensively drug-resistant and pandrugresistant bacteria : an international expert proposal for interim standard definitions for acquired resistance. Clin Microbiol Infect, 18(3):268-281.

Mahdiyoun SM, Kazemian H, Ahanjan M, Houri H and Goudarzi M .2016. Frequency of aminoglycoside-resistance genes in methicillin-resistant Staphylococcus aureus (MRSA) isolates from hospitalized patients. Jundishapur J Microbiol, 9(8): e35052.

McTavish, SM, Snow SJ, Cook EC, Pichon B, Coleman S, Coombs GW, Pang S, Arias CA, Díaz L, Boldock E, Davies S, Udukala M, Kearns AM, Siribaddana S and de Silva TI.2019. Genomic and epidemiological evidence of a dominant PantonValentine leucocidin-positive Methicillin Resistant Staphylococcus aureus lineage in Sri Lanka and presence among 
isolates from the United Kingdom and Australia. Front Cell Infect Microbiol, 9(123):1-6.

Młynarczyk A, Szymanek-Majchrzak K and Młynarczyk G .2010. Occurrence of aminoglycoside transpherase genes in methicillinresistant strains of Staphylococcus aureus. Med Dośw Mikrobiol, 62(4):289-295.

Mohammadi S, Sekawi Z, Monjezi A, Maleki M-H, Soroush S, Sadeghifard N, Pakzad I, Azizi-Jalilian F, Emaneini M, Asadollahi K, Pourahmad F, Zarrilli R and Taherikalani M.2014. Emergence of SCCmec type III with variable antimicrobial resistance profiles and spa types among methicillin-resistant Staphylococcus aureus isolated from healthcare-and communityacquired infections in the west of Iran. Int J Infect Dis, 25:152158.

Munger LL and Kelly BL.1973. Staphylococcal granulomas in a Leghorn hen. Avian Dis, 17:858-860.

Namvar AE, Havaei SA, Azimi L, Lari AR and Rajabnia R .2017. Molecular characterization of Staphylococcus epidermidis isolates collected from an intensive care unit. Arch Pediatr Infect Dis, 5(2) :e36176.

Navidinia M, Amirpour A, Goudarzi M, Pouriran R, and Tabrizi MS. 2019. Diversity of prophages, spa, and SCCmec types in Methicillin-Resistant Staphylococcus aureus strains isolated from burn patients: A study in a referral burn hospital in Tehran, Iran. Mol Genet Microbiol Virol, 34:124-130.

Peacock SJ and Paterson GK.2015.Mechanisms of methicillin resistance in Staphylococcus aureus. Annu Rev Biochem, 84(1):577-601.

Perumal N, Murugesan S and Krishnan P .2016. Distribution of genes encoding aminoglycoside-modifying enzymes among clinical isolates of methicillin-resistant staphylococci.IJMM, 34(3): 350

Ramirez MS and Tolmasky ME .2010. Aminoglycoside modifying enzymes. Drug Resist Updat,13:151-171.

Razeghi M, Saffarian P and Goudarzi M .2019. Incidence of inducible clindamycin resistance and antibacterial resistance genes variability in clinical Staphylococcus aureus strains: A twoyear multicenter study in Tehran, Iran. Gene Reports, 16: 100411.

Riaz S, Faisal M and Hasnain S .2011. Antibiotic susceptibility pattern and multiple antibiotic resistances (MAR) calculation of extended spectrum $\beta$-lactamase (ESBL) producing Escherichia coli and Klebsiella species in Pakistan. Afr J Biotechnol, 10 (33):6325-6331.

Riesen A and Perreten V .2009. Antibiotic resistance and genetic diversity in Staphylococcus aureus from slaughter pigs in Switzerland. Schweiz Arch Tierheilkd, 151(9):425-431.

Seyedi-Marghaki F, Kalantar-Neyestanaki D, Saffari F, HosseiniNave H, and Moradi M .2019. Distribution of Aminoglycoside- modifying enzymes and molecular analysis of the coagulase gene in clinical isolates of methicillin-resistant and methicillinsusceptible Staphylococcus aureus. Microb Drug Resist, 25(1), 47-53.

Szymanek-Majchrzak K, Mlynarczyk A, Kawecki D, Pacholczyk M, Durlik M, Deborska-Materkowska D, Paczek L and Mlynarczyk G .2018a. Resistance to Aminoglycosides of Methicillin-Resistant Strains of Staphylococcus aureus, Originating in the Surgical and Transplantation Wards of the Warsaw Clinical Center-A Retrospective Analysis. Transplant Proc, 50(7):2170-2175.

Szymanek-Majchrzak K, Mlynarczyk A and Mlynarczyk G .2018b. Characteristics of glycopeptide-resistant Staphylococcus aureus strains isolated from inpatients of three teaching hospitals in Warsaw, Poland. Antimicrob Resist Infect Control, 7(105): 1-6.

Vakulenko SB, Donabedian SM, Voskresenskiy AM, Zervos MJ, Lerner SA and Chow JW.2003. Multiplex PCR for detection of aminoglycoside resistance genes in enterococci. Antimicrob Agents Chemother, 47: 1423-1426.

Vakulenko SB and Mobashery S .2003. Versatility of aminoglycosides and prospects for their future. Clin Microbiol Rev, 16:430-450.

Vanhoof R.1994. Detection by polymerase chain reaction of genes encoding AMEs in methicillin-resistant Staphylococcus aureus isolates of epidemic phage types. J Med Microbiol, 41:282-290.

Watkins RR, Holubar M and David MZ .2019. Antimicrobial resistance in methicillin-resistant Staphylococcus aureus to newer antimicrobial agents. Antimicrob Agents Chemother, 63(12): e01216-19.

World Health Organization .2017. Global priority list of antibiotic-resistant bacteria to guide research, discovery, and development of new antibiotics. Geneva, Switzerland.

Xu F, Chen J, Xiao C, Cong F, Ma L, Moore RJ, Huang R. and Guo P .2019. Development of a Luminex xTAG Assay for the Rapid Detection of Five Aminoglycoside Resistance Genes Both in Staphylococci and Enterococci. Microb Drug Resist, 25(6): 874-879.

Yadegar A, Sattari M, Mozafari NA and Goudarzi GR .2009. Prevalence of the genes encoding aminoglycoside-modifying enzymes and methicillin resistance among clinical isolates of Staphylococcus aureus in Tehran, Iran. Microb Drug Resist, 15(2):109-113.

Zacharczuk K, Piekarska K, Szych J, Jagielski M, Hidalgo L, San Millan A, Gutiérrez B, Rastawicki W, González-Zorn B and Gierczynski R .2011. Plasmid-borne 16S rRNA methylase ArmA in aminoglycoside resistant Klebsiella pneumoniae in Poland. J Med Microbiol, 60 (9) :1306-1311. 